06

\title{
Диэлектрические потери в насыщенном водородом титане ВT1-0 при распространении в нем вихревых токов
}

\author{
() Ш. Сюй, В.В. Ларионов, А.М. Лидер \\ Томский политехнический университет, \\ 634050 Томск, Россия \\ e-mail: Ivv@tpu.ru
}

Поступило в Редакцию 9 апреля 2018 г.

В окончательной редакции 3 июля 2019 г.

Принято к публикации 3 июля 2019 г.

Исследованы диэлектрические потери $\operatorname{tg} \delta$ в насыщенном водородом титане в интервале концентрации водорода в титане ВТ1-0 от 190 до $2900 \mathrm{ppm}$ в диапазоне частот вихревых токов 200-1000 kHz. Зависимость $\operatorname{tg} \delta$ от частоты имеет два хорошо выраженных пика, что свидетельствует о неравномерном распределении водорода в титане по глубине образца. Предполагается, что данным методом можно определять концентрацию водорода в насыщенном водородом металле ВТ1-0.

Ключевые слова: водород, титан, вихревые токи, диэлектрические потери.

DOI: 10.21883/JTF.2020.01.48668.143-18

\section{Введение}

Диэлектрические свойства различных веществ и материалов, таких как диэлектрики, полупроводники, плазма и др., являются важными [1-3] и анализируются путем введения понятия тангенса угла диэлектрических потерь. В настоящей работе эта величина использована для анализа насыщенного водородом технического титана ВТ1-0 [2,3]. Исследование этой величины позволяет с высокой чувствительностью измерять распределение водорода в образце титана в зависимости от глубины. Известно, что диэлектрические потери в исследуемом материале связаны с особенностями его структуры. В веществах с плотной упаковкой атомов в присутствии примесей, дефектов, дислокаций, искажающих решетку, диэлектрические потери возрастают. Обычно потери связывают с явлением поляризации (первый вид) и изменением электропроводности (второй вид). На это указывают измерения электропроводности в работе [3]. При этом, как показывает экспериментальные данные, примеси даже в малом количестве резко увеличивают диэлектрические потери. Так, в диапазоне частот от 10 до $10^{4} \mathrm{~Hz}$ тангенс угла диэлектрических потерь во многих веществах изменяется на три порядка [3]. Наблюдаются потери, возрастающие с увеличением частоты, и потери, заметно возрастающие с увеличением температуры. В любом случае $\operatorname{tg} \delta$ изменяется с изменением частоты приложенного к образцу внешнего силового поля. Такая зависимость в литературных источниках приписывается дипольному характеру структуры материала. Потери первого вида объясняются релаксационной поляризацией. Они, например, сильно выражены в веществах с ионной структурой. Чистые вещества обладают небольшими релаксационными потерями. Введение примесей может привести к возрастанию диэлектриче- ских потерь вследствие нарушения структуры, например, титанового сплава. Причины большого различия в диэлектрических потерях объясняются тем, что электронная поляризация в диэлектриках устанавливается за различные времена. Коэффициент потерь меняется с изменением частоты, содержания примесей, температуры и влажности. Содержание добавок, например, в композиционных материалах, также сопровождается изменением значений $\operatorname{tg} \delta$. Как правило, потери имеют максимум при одной или нескольких частотах в зависимости от типа молекул [2,3]. Положение максимумов характеризуется собственными частотами установления поляризации. Они могут быть связаны с поворотом полярных молекул в жидком диэлектрике или с поворотом домена в сегнетоэлектрике. Частотная зависимость потерь является характеристикой материала и определяется для каждого материала не только свойствами его молекул, но и наличием и составом примесей. Целью настоящей работы является исследование возможности применения обсуждаемого метода для анализа содержания водорода в гидрированных металлах на примере титана.

\section{Материалы и методы}

Для исследования использован технический чистый титан VT1-0. Состав титанового сплава [wt.\%]: $0.18 \mathrm{Fe}$, $0.1 \mathrm{Si}, 0.07 \mathrm{C}, 0.12 \mathrm{O}, 0.01 \mathrm{H}, 0.04 \mathrm{~N}$. Образцы изготавливали из сплава ВТ1-0 различной толщины от 1 до $10 \mathrm{~mm}$ методом электроискровой резки. Насыщение водородом осуществлялось по методу Сивертса из газовой фазы при температуре $600^{\circ}$ и давлении $2 \mathrm{~atm}$ аналогично [4,5]. Содержание водорода в образцах определяли на анализаторе RHEN 602 фирмы LECO. Измерение активной и реактивной составляющей вихревого тока в насыщенных водородом образцах проводили на магнитном спектраль- 

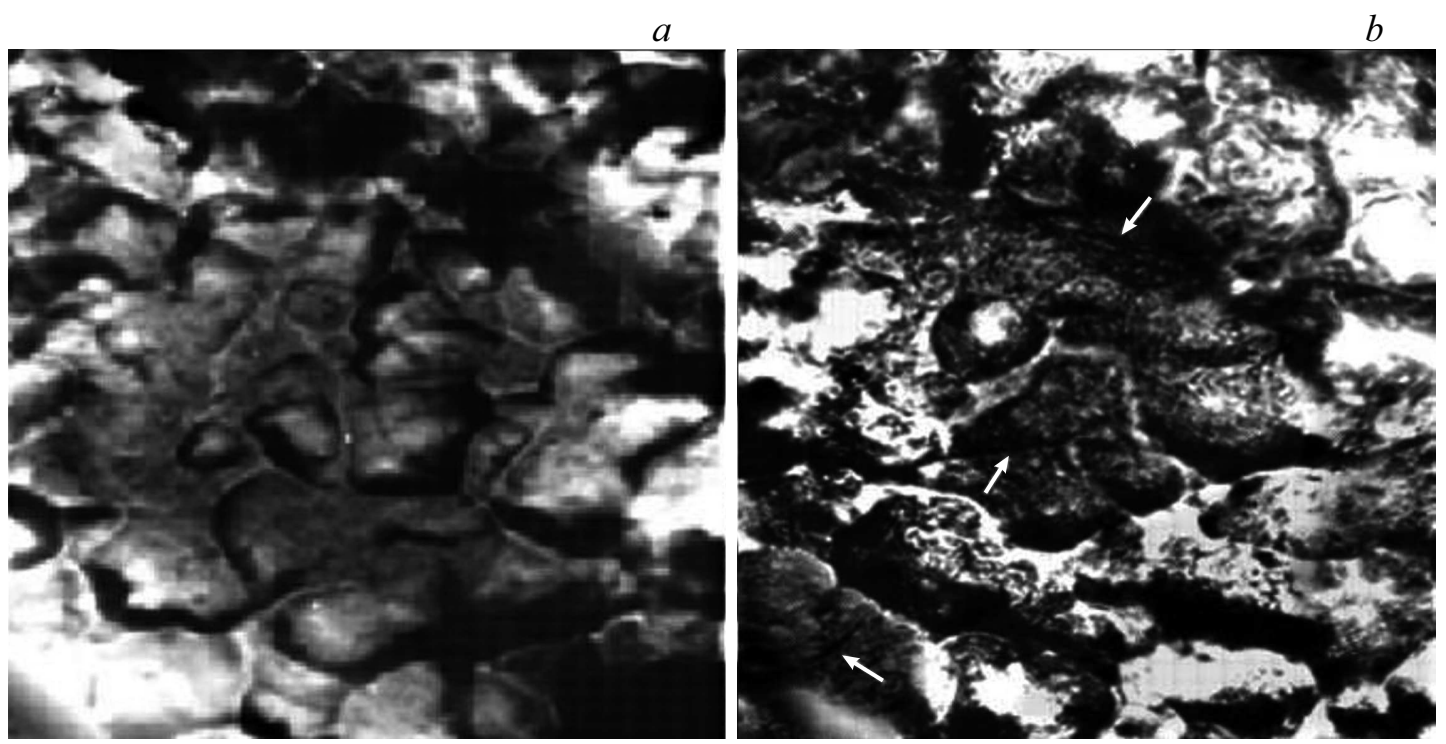

Рис. 1. Образец титана ВТ1-0 до (a) и после насыщения водородом $(b)$ (металлография X 1000). Стрелками показано направление положения датчика магнитного спектрального анализатора.

ном анализаторе ZMA-II (Германия) [5]. Дополнительно образцы исследовали с помощью оптического Olympus GX-71 и сканирующего микроскопов (микроскоп Philips SEM 515).

\section{Результаты и обсуждение}

Насыщение металлов водородом и в частности титана ВТ1-0 приводит к изменению структуры металла, образованию дефектов, зерен разных размеров и ориентации [6-8]. На рис. 1 приведены изображения структуры титана, полученные до и после наводороживания. Микроструктурные исследования боковой грани образцов ВT1-0, подвергнутых насыщению водородом, показывают, что увеличение содержания водорода до 165 ppm не приводит к формированию гидридной фазы. При увеличении концентрации водорода выше 600 ppm в объеме образцов наблюдается выделение пластинчатого гидрида титана [8]. Так как вихревые токи на разных частотах проникают на различную глубину, то соответственно концентрация водорода должна существенно влиять на величину диэлектрических потерь вихревых токов.

Для исследованных концентраций водорода в титане характерны две ветви для зависимости $\operatorname{tg} \delta$ - возрастающая и ниспадающая (рис. 2), и два пика (рис. 3). Если на частоте $250 \mathrm{kHz}$ наибольший максимум наблюдается при концентрации $1760 \mathrm{ppm}$, то на частоте $550 \mathrm{kHz}$ максимум соответствует концентрации $190 \mathrm{ppm}$. Возможно, это вызвано тем, что глубина проникновения вихревых токов на частоте $250 \mathrm{kHz}$ примерно в 1.4 раза больше, чем при $550 \mathrm{kHz}$. Количество дефектов, вызванных насыщением титана водородом, соответственно возрастает. С другой стороны, это может быть связано c образованием гидридов титана $\mathrm{TiH}_{x}$ при концентрации

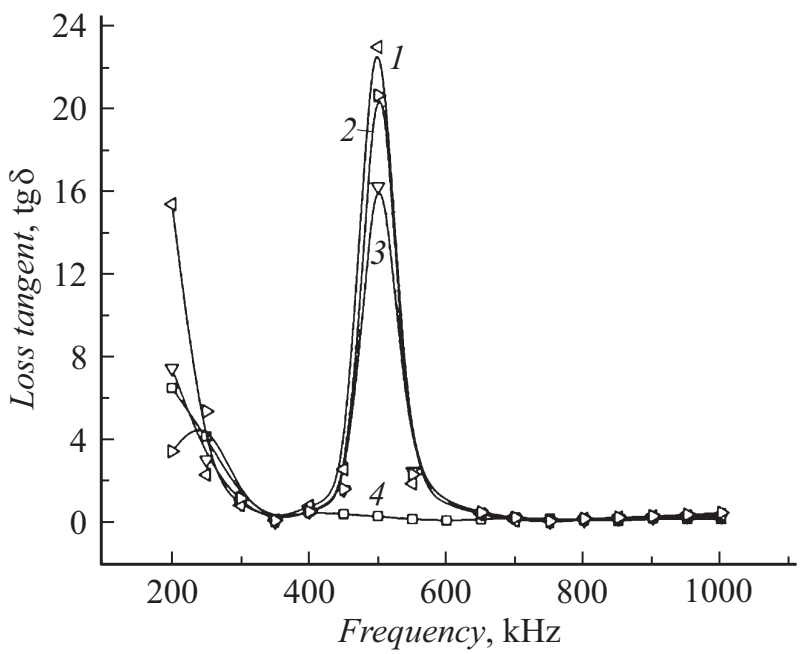

Рис. 2. Зависимость тангенса угла диэлектрических потерь для насыщенного водородом титана от частоты вихревого тока: 1 - 380, 2 - 930, 3 - 690 ppm, 4 - технический титан (не содержит водород).

$C_{\mathrm{H}}=1760$ ррт или с изменением размеров зерен и их ориентации.

Именно поэтому следует изменять угловое положение датчика на поверхности исследуемого образца. Различие в составе, как отмечено в $[9,10]$, соответствует различной степени поляризации исследуемой среды. Это также является возможным объяснением полученных зависимостей. При частотах больше $600 \mathrm{kHz}$ различие в диэлектрических потерях теряется, так как в приповерхностном слое состав и структура образца, скорее всего, определяются слоем окисла титана. Значение $\operatorname{tg} \delta$ возрастает при увеличении частоты вихревого тока. 


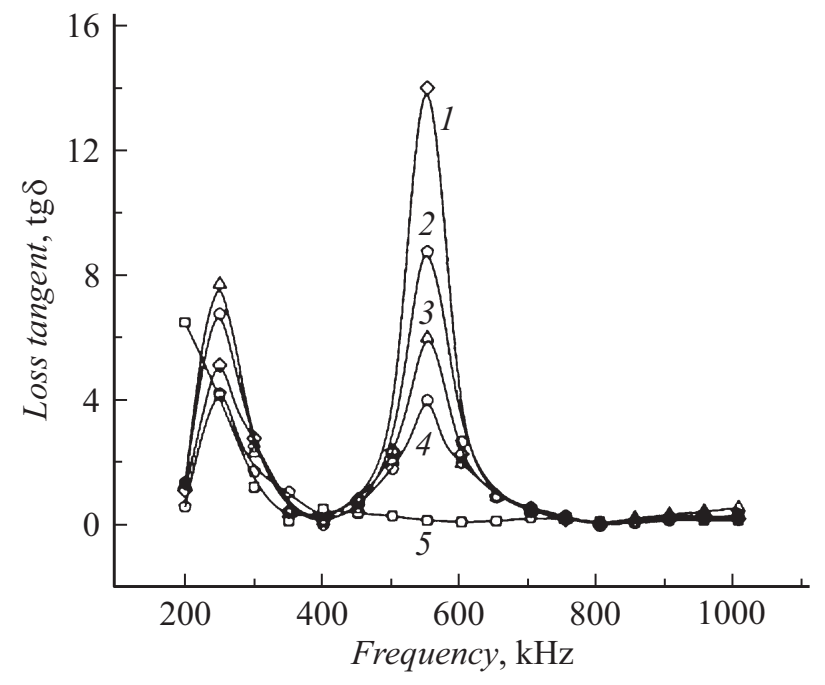

Рис. 3. Зависимость тангенса угла диэлектрических потерь для насыщенного водородом титана ВТ1-0 от частоты вихревого тока: $1-190,2-1200,3-1760,4-2900$ ppm, 5 - технический титан (не содержит водород).

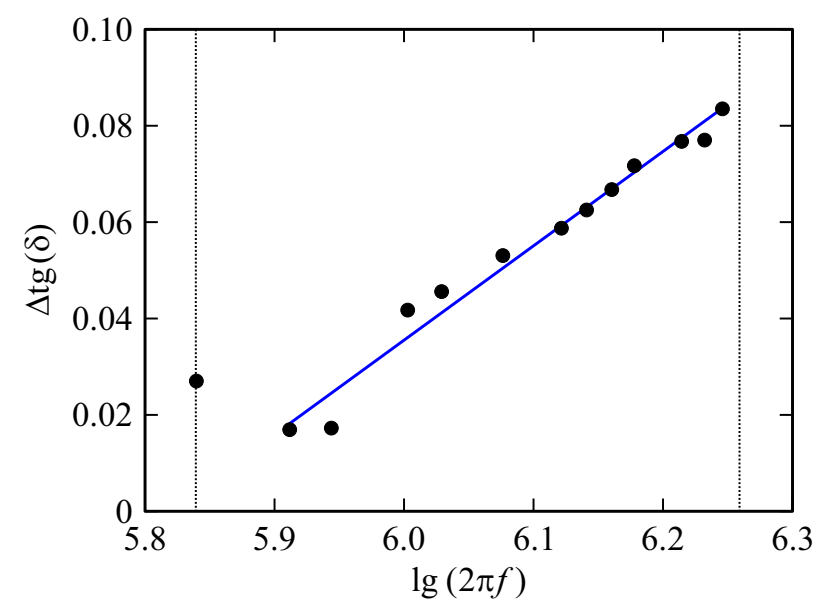

Рис. 4. Зависимость изменения тангенса угла диэлектрических потерь для насыщенного водородом титана ВТ1-0 от частоты вихревого тока.

На рис. 2 эта частота составляет около $400 \mathrm{kHz}$, на pис. $7-350 \mathrm{kHz}$. Подчеркнем, что тангенс угла диэлектрических потерь образца титана без водорода не содержит пиковых значений. Именно содержание водорода как „примеси“ в исследуемом образце влияет на значение потерь [11-13]. Подчеркнем, что для образцов с различным содержанием водорода изменяется не только пиковое положение значений диэлектрических потерь, но и величина максимума пика.

Наконец, когда частота велика, то, по-видимому, диэлектрическая проницаемость определяется только смещением поляризации и $\operatorname{tg} \delta \rightarrow 0$. Зависимость разности логарифмов тангенса угла диэлектрических потерь для разных концентраций водорода $C_{\mathrm{H}}$ в титане ВТ1-0 от частоты вихревого тока представляет прямую (рис. 4).
Пример дан для образцов, концентрация водорода в которых изменяется от 1200 до 2900 ppm. Следовательно, величина $\Delta \operatorname{tg}(\delta)$ диэлектрических потерь может быть полезна для оперативного анализа свойств титана насыщенного водородом.

\section{Заключение}

Исследованы диэлектрические потери для титана BT1-0 при изменении концентрации водорода в нем от 1200 до 2900 ppm методом вихревых токов. В диапазоне частот 250 и $550 \mathrm{kHz}$ зарегистрированы два пика зависимости $\operatorname{tg} \delta$ от частоты, причем для различных концентраций водорода. Отмечается инверсия пиковых значений диэлектрических потерь на данных частотах для разных концентраций водорода в титане. В диапазоне частот $400-650 \mathrm{kHz}$ величина $\Delta \operatorname{tg}(\delta)$ диэлектрических потерь линейно зависит от частоты. Это позволяет использовать данную зависимость для оперативного определения содержания водорода в титане. Полученные экспериментальные результаты показывают, что диэлектрические потери в титане существенно зависят от структуры и внутренних связей, образующихся при его насыщении водородом.

\section{Финансирование работы}

Исследование финансируется за счет гранта Программы повышения конкурентоспособности Томского политехнического университета.

\section{Конфликт нтересов}

Авторы заявляют, что у них нет конфликта интересов.

\section{Список литературы}

[1] Liang Z., Shuo C., Shuai Y., Dongrui W., Peng-Hao H., Zhi-Min D. // Appl. Phys. Lett. 2014. Vol. 105. P. 1-4.

[2] Robert C.P., Stuart J.P., Xiaoru W., Ian M.R., Neil McN. Alford // J. Europ. Ceramic Society. 2009. Vol. 29. N 3. P. 419-424.

[3] Калыгина В.М., Зарубин А.Н., Новиков В.А., Петрова Ю.С., Скакунов М.С., Толбанов О.П., Тяжев А.В., Яскевич Т.М. // ФТП. 2010. Т. 44. Вып. 9. С. 1266-1273.

[4] Larionov V.V., Shupeng Xu, Syrtanov M.S. // AIP Conf. Proceed. 2016. Vol. 1772. P. 040005. https://doi.org/10.1063/1.4964564

[5] Сюй Ш., Ларионов В.В. // Сб. научных трудов XIV Междунар. конф. Томск, 2017. Т. 1. С. 336-338.

[6] Evard E.A., Gabis I.E., Voyt A.P. // J. Alloys Compounds. 2005. Vol. 404-4-6. P. 335-338.

[7] Panin A.V. // Appl. Surf. Sci. 2013. Vol. 284. P. 750-756.

[8] Панин А.В., Панин В.Е., Почивалов Ю.И., Клименов В.А., Чернов И.П., Валиев Р.З., Казаченок М.С., Сон А.А. // Физическая мезомеханика. 2002. Т. 5. № 4. С. 73-84. 
[9] Wypych A., Bobowska I., Tracz M., Opasinska A., Kadlubowski S., Krzywania-Kaliszewska A., Grobelny J., Wojciechowski P. // J. Nanomater. 2014. Article ID 124814. doi.10.115/2014/124814

[10] Yu S., Yang S., Penghao H., Yuanhua L., Ming L., Nan C.W. // Appl. Phys. Lett. 2012. Vol. 101. P. 1-4.

[11] Fares S. // Natural Sci. 2011. Vol. 3. N 12. P. 1034-1039.

[12] Obrzut J., Anopchenko A., Kano K., Wang H. // Mat. Res. Soc. Symp. Proc. 2004. Vol. 783. P. 1-6.

[13] Карпов А.Г., Клемешев В.А. // ЖТФ. 2018. Т. 88. Вып. 4. C. 634-637. 